\title{
Testes aritméticos no cotidiano da Escola Normal de Casa Branca
}

\author{
Arithmetic tests in everyday Escola Normal Casa Branca
}

Nara Vilma Lima Pinheiro ${ }^{1}$

\begin{abstract}
Resumo
Este artigo analisa as tentativas da Escola Normal de Casa Branca de dar base científica à organização escolar em tempos da pedagogia experimental. Trata-se de um tempo em que os discursos científicos orientavam a transformação das escolas em verdadeiros laboratórios para diagnosticar os problemas educacionais e dar-lhes a cura por meio de métodos de ensino adequados. Fundamentado nos estudos advindos da História Cultural, buscou-se analisar o estabelecimento dos testes na cultura escolar para subsidiar mudanças na prática pedagógica do ensino de Aritmética. Tem-se como questão norteadora saber: que usos e interpretações da pedagogia experimental fez a Escola Normal de Casa Branca para o ensino de Aritmética, tendo-se como obra referência a Introdução ao Estudo da Escola Nova? O estudo evidenciou que ainda não estavam em foco questões relativas à aprendizagem aritmética, o que se tinha era uma preocupação com o desenvolvimento psicológico da criança com vistas a um maior rendimento do ensino.
\end{abstract}

Palavras-chave: Pedagogia Experimental, testes pedagógicos, Aritmética, escola primária

\begin{abstract}
This article analyzes the attempts of the Escola Normal of the Casa Branca to give science-based school organization in times of experimental pedagogy. It is a time that scientific discourse guided the transformation of schools into real laboratories to diagnose educational problems and give them the cure through appropriate teaching methods. Using as theoretical framework the studies arising from cultural history, this article proposes to examine the establishment of the tests in school culture to support changes in the pedagogical practice of teaching arithmetic. It has been guiding question as follows: what uses and interpretations of experimental pedagogy made the Escola Normal de Casa Branca for numeracy, having as main reference the work Introdução ao Estudo da Escola Nova? The study showed that is not yet in focus issues related to learning arithmetic, what you have is a concern for the child's psychological development in order to have a higher yield of education.
\end{abstract}

Keywords: Experimental Pedagogy, pedagogical tests, arithmetic, primary school

\section{Introdução}

O século XIX testemunhou a multiplicação de pesquisas em alguns países, notadamente nos EUA, que visavam ao estudo psicológico da infância. Mas veio da França, dos estudos de Alfred Binet, a contribuição mais significativa ${ }^{2}$.

\footnotetext{
${ }^{1}$ Doutoranda do Programa de Educação e Saúde na Infância e na Adolescência da Universidade Federal de São Paulo/Unifesp, Guarulhos, São Paulo, Brasil. E-mail: naravlp@yahoo.com.br. A pesquisa recebe financiamento da CAPES/COFECUB.
} 
http://periodicos.sbu.unicamp.br/ojs/index.php/zetetike

A ideia central dos estudos de Binet era identificar as diferenças psicológicas individuais a fim de estabelecer uma classificação. Seus estudos resultaram na elaboração da psicologia individual, fundamentada no método que deveria ser mais científico do que filosófico. Além de se dedicar à psicologia experimental, nos últimos anos de sua vida, Binet se ocupou em aplicar o método experimental aos problemas pedagógicos (Avanzinni, 1969). E foi no ambiente escolar que ele encontrou o lugar privilegiado, pois ali a diversidade de sujeitos se manifestaria mais claramente em relação ao rendimento, ao ritmo de aquisição de conhecimentos, aos modos de compreensão e de memorização de conceitos ensinados. Uma observação detalhada favoreceria revelar o nível intelectual de cada um e comparar uns com os outros. Tomando as crianças mal adaptadas à escola primária e as crianças anormais de hospício, Binet, em parceria com o médico francês Theodore Simon (1872-1961), colocou em prática métodos experimentais para diagnosticar o nível intelectual das crianças. Essa prática experimental resultou na publicação da Échelle Métrique de l'intelligence, em 1905.

Inicialmente essa escala foi criada para diagnosticar os anormais, mas, posteriormente, ela passou a ser aplicada aos alunos das classes primárias. A escala constituise de "uma série de provas de dificuldade progressiva, que partem, de um lado, do mais baixo nível intelectual que se possa observar, até, por outro lado, atingem o nível da inteligência mediana e normal, a cada prova corresponde um nível diferente" (Nihard, 1946, p. 67).

Os estudos de Binet evidenciaram duas categorias para estudar a pedagogia pelo método experimental. A primeira, denominada de pedagogia individual, se propunha a estudar as capacidades de cada criança; e a segunda, conhecida como pedagogia geral, tinha por objetivo a determinação dos métodos de ensino. Para Binet, os métodos de ensino não poderiam ser determinados antes de serem conhecidas as capacidades das crianças. Seus estudos ganharam proporções mundiais e também chegaram ao Brasil.

Em terras paulistas, um dos maiores defensores da pedagogia experimental, fundamentada na psicologia individual, foi Lourenço Filho ${ }^{3}$. Assim como Binet, ele também defendia que a pedagogia se dividia em dois ramos principais e distintos: a clínica - que seriam os meios de diagnósticos; e a terapêutica ou didática - que realizaria uma intervenção direta sobre os indivíduos para curá-los ou educá-los. (Lourenço Filho, 1930). A pedagogia clínica permitiria, por meio dos testes, determinar a capacidade de aprender, a organização de classes o mais homogênea possível e a graduação e seriação do ensino em relação à idade, para uma maior eficiência do ensino. Diagnosticadas as capacidades dos alunos, a pedagogia terapêutica adotaria os métodos adequados para curá-los ou educá-los.

\footnotetext{
2 Alfred Binet (1857-1911) doutor em Ciências pela Universidade de Paris, "destacou-se especialmente na construção de estratégias metodológicas de investigação psicológica, num modelo de ciência aplicada, capaz de intervir na vida social" (Campos, Gouvea \& Guimarães, 2014, p.218).

3 Manuel Bergström Lourenço Filho (1897-1970), pedagogo brasileiro e grande divulgador das ideias escolanovistas.
}

Zetetiké, Campinas, SP, v.24, n.2, maio/ago.2016, p.225-236

ISSN 2176-1744 
http://periodicos.sbu.unicamp.br/ojs/index.php/zetetike

Há esse tempo, o termo diagnóstico, tomado de empréstimo da medicina, era usado identificar os sintomas dos doentes a fim de prescrever o tratamento adequado. Tratava-se de diagnosticar para, em seguida, tratar e curar. $\mathrm{O}$ uso desse termo na educação evidenciava o propósito de detectar, mediante os testes de cada aluno, os problemas que dificultavam a eficiência do ensino. Na educação, o tratamento se daria por meio de métodos adequados. Em relação a esses métodos, Lourenço Filho (1930) sugeria três: o método de Montessori ${ }^{4}$ fundamentado na psicologia clássica e de tendência analista; o método de Decroly ${ }^{5}$ - ainda em fase de transição pelo autor; e o sistema de projetos de Dewey ${ }^{6}$ - considerado o mais completo.

Na década de 1930, o ambiente escolar se viu transformado num laboratório para coleta de material, para observação, para diagnóstico e para cura, buscando estudar de modo científico os fenômenos escolares sob o ângulo da economia de tempo e melhoria do rendimento. A renovação pedagógica visava à "necessidade de verificação objetiva dos elementos da educação e de cada passo do aprendizado". Nesse sentido, os testes ganhavam destaque no ambiente escolar, por substituir a "apreciação subjetiva do aluno e de seu trabalho por parte do mestre" (Lourenço Filho, 1930, p. 48). As experiências com testes nas escolas se intensificaram durante a gestão de Lourenço Filho na Diretoria Geral da Instrução Pública de São Paulo, no período de 1931 a 1932, em especial com a criação do Serviço de Psicologia Aplicada - SPA ${ }^{7}$. Fundamentado na psicologia experimental, Lourenço Filho defendia que a criança não aprenderia "em qualquer idade, qualquer coisa", e que o ensino deveria ser adaptado ao desenvolvimento natural da criança e não mais segundo o "plano lógico das técnicas organizadas pelos adultos". (Lourenço Filho, 1930, p. 61). Nesse sentido, os programas não poderiam ser organizados a priori, mas, sim, adequados ao desenvolvimento psicológico da criança.

As ideias de Lourenço Filho serviram de inspiração para algumas escolas normais paulistas, como, por exemplo, a Escola Normal de Casa Branca que adotou a reorganização escolar e os novos métodos de ensino, ambos fundamentados na pedagogia científica de caráter experimental. As experiências desenvolvidas nessa e em outras Escolas Normais se deram na gestão de Almeida Júnior ${ }^{8}$ na Diretoria Geral da Instrução Pública de São Paulo, em

\footnotetext{
4 Maria Montessori (1870-1952), médica e pedagoga italiana, conhecida mundialmente por seu método pedagógico.

${ }^{5}$ Jean-Ovide Decroly (1871-1932), médico, pedagogo e psicólogo belga. Simpatizante do movimento da Escola Nova, ele defendia o método global.

${ }^{6}$ John Dewey (1859-1952) psicólogo e filósofo americano. Defendia o movimento da Escola Nova.

${ }^{7}$ Instituição criada em 1931, subordinada à Secretaria de Educação e Saúde Pública do Estado de São Paulo e instalada nas dependências da Escola Normal da Praça. Posteriormente, o SPA passou a denominar-se Laboratório de Psicologia Educacional (Baptista, 2001).

${ }^{8}$ Antonio Ferreira de Almeida Júnior (1892-1971), professor pela Escola Normal da Praça (1909), médico pela Faculdade de Medicina e Cirurgia de São Paulo (1921), chefe do serviço médico escolar do estado de São Paulo (1933), diretor de ensino da Secretaria da Educação de São Paulo (1936 - 1938).
}

Zetetiké, Campinas, SP, v.24, n.2, maio/ago.2016, p.225-236

ISSN 2176-1744 
http://periodicos.sbu.unicamp.br/ojs/index.php/zetetike

1936. Segundo Almeida Júnior (1936, p. 04), as Escolas Normais, tais como: Instituto de Educação (antiga Escola Normal da Praça), Escola Normal Carlos Gomes (Campinas), Escola Normal de Guaratinguetá e Escola Normal Padre Anchieta ${ }^{9}$ (antiga Escola Normal Primária do Brás), estavam "profundamente impregnadas do espírito de remodelação pedagógica, e animadas por um enthusiamo reconfortante de iniciativa e inovações".

Para este artigo, interessou-nos analisar como se deu a apropriação da pedagogia experimental na escola primária anexa à Escola Normal de Casa Branca na década de 1930, tendo como principal referência as ideias de Lourenço Filho, publicadas no livro Introdução ao estudo da escola nova. Para tanto, tomamos como fonte de pesquisa o Relatório das atividades desenvolvidas no curso primário anexo à Escola Normal de Casa Branca (1936), cujas bases revelam claramente a influência de Lourenço Filho, desde a fundamentação, passando pela organização e pelas várias citações a esse intelectual. Além disso, o próprio relatório constitui verdadeiro retrato de um tempo de transformação das lides escolares diante dos novos conhecimentos científicos sobre o desenvolvimento psicológico da criança e dos estágios de maturação. Nele, a diretora Maria Ari Fonseca ${ }^{10}$ fez uma exposição das experiências realizadas a partir dos resultados da aplicação de testes nas classes primárias da referida escola. Acreditamos que as experiências desenvolvidas no curso primário anexo à Escola Normal de Casa Branca são um caso modelar dos processos que ocorreram nas escolas sob o impacto de uma era cientificizante na Educação.

Nossa análise estará fundamentada na noção de apropriação de Chartier (2002, p. 136). Trata-se de um conceito fundamental da obra desse autor que considera que as práticas culturais se apropriam de diferentes maneiras dos textos que circulam em uma determinada sociedade e dão lugar a "usos diferenciados e opostos dos mesmos bens culturais, dos mesmos textos e das mesmas ideias", para além das intenções iniciais. Visto dessa forma, interessou-nos, neste estudo, saber que usos e interpretações da pedagogia experimental fez a Escola Normal de Casa Branca para o ensino de Aritmética, tendo-se como obra referência a Introdução ao Estudo da Escola Nova.

\section{A Pedagogia Experimental no cotidiano escolar}

A primeira providência da Escola Normal de Casa Branca em busca de uma renovação pedagógica foi, tal como a sugerida por Lourenço Filho (1930), a organização de classes homogêneas para maior rendimento do ensino. Esses tipos de classes tinham por objetivos dar tratamento adequado à capacidade de cada criança, individualizar o ensino e oferecer uma maior assistência aos identificados como débeis mentais e supernormais. A organização das classes desse modo diminuiria o número de reprovações e facilitaria o

\footnotetext{
${ }^{9}$ Sobre as experiências com testes para o ensino de Aritmética, desenvolvidas nessa escola, ver Pinheiro (2015).

${ }^{10}$ Até a escrita de artigo, pouco se sabe sobre Maria Ari Fonseca, apenas que ela foi diretora da Escola Normal de Casa Branca em 1936 e fez parte do quadro docente da Escola Normal Carlos Gomes de Campinas em 1941.
}

Zetetiké, Campinas, SP, v.24, n.2, maio/ago.2016, p.225-236

ISSN 2176-1744 
http://periodicos.sbu.unicamp.br/ojs/index.php/zetetike

controle do trabalho do professor, significando uma economia aos cofres públicos. Nessa etapa, a psicologia interviria antes do ensino. Então, o ponto de partida foi realizar, por meio de testes $\mathrm{ABC}^{11}$, a organização de classes homogêneas para o $1^{\circ}$ ano para verificar a maturidade dos alunos para leitura e escrita. Com o resultado dos testes, os alunos foram divididos em três classes: $\mathrm{A}, \mathrm{B}$ e $\mathrm{C}$, sendo a classe $\mathrm{A}$ dos alunos mais fracos. Mas não basta apenas separar os alunos "se a escola não está organizada no sentido dos vários sistemas renovados de educação, a homogeneização das classes em nada contribuirá para o rendimento social dos indivíduos". Era necessário, então, rever a "dynâmica da aprendizagem", isto é, a maneira de ensinar, pois "de cada nova filosofia do espírito, decorre uma nova atitude em face do problema do ensino" (Lourenço Filho, 1930, p. 15). Sobre a dinâmica da aprendizagem, trataremos no item seguinte.

Os testes serviriam não só para a classificação dos alunos, sua técnica (base estatística e aplicação), mas também para "fornecer elementos para a organização da medida objectiva de todo trabalho do mestre" (Lourenço Filho, 1930, p. 15). Permitiria, ainda, de modo objetivo, efetivar a comparação entre os alunos, entre duas classes, entre o trabalho dos professores, etc. Entretanto não eram processos de ensino, mas, sim, meios de verificação de elementos para "úteis transformações dos processos em uso, substituindo o critério do julgamento subjetivo dos mestres e administradores pelo critério objetivo da sciencia" (Lourenço Filho, 1930, p. 15).

Nessa perspectiva, esperava-se que os testes pedagógicos, empregados no decorrer do ensino, auxiliassem na prática pedagógica do professor, que escolheria os métodos de ensino adequados para solucionar os problemas indicados pela utilização dos recursos psicológicos. Esses testes seriam organizados pela própria escola a partir dos conteúdos ministrados nas classes, pois apenas o programa de ensino não bastaria para a organização de testes, visto que os professores não desenvolviam os conteúdos do programa na mesma ordem e do mesmo modo. Então, cada professor deveria organizar um quadro de especificação, para, posteriormente, ser submetido à comparação com outros quadros, para escolha dos conteúdos que melhor se adaptariam aos testes. O quadro de especificação era um plano de ação para a estandardização de testes, no qual seria necessário definir a habilidade que seria avaliada, o objetivo dos testes e a maneira de se avaliar. Em resumo, o quadro de especificação seria uma maneira de assegurar que os resultados visados seriam avaliados. (Registro das Reuniões, 1931 - 1932). Em se tratando da Aritmética, quais habilidades seriam avaliadas? Que objetivos teriam esses testes?

Na organização dos quadros de especificação, a administração da Escola de Casa Branca constatou que os alunos do primeiro ano das classes B e $\mathrm{C}$ se desenvolveram mais rapidamente do que os da classe $\mathrm{A}$, isto dificultou a elaboração de questões para os testes pedagógicos que atendessem às porcentagens estabelecidas pela estatística $(25 \%$ de questões

\footnotetext{
${ }^{11}$ Bateria de testes publicada em 1933 com o objetivo de diagnosticar precocemente a maturidade psicológica das crianças, a aquisição da leitura e escrita e a homogeneização das classes (Monarcha, 2009, p. 13).
}

Zetetiké, Campinas, SP, v.24, n.2, maio/ago.2016, p.225-236

ISSN 2176-1744 
http://periodicos.sbu.unicamp.br/ojs/index.php/zetetike

fortes, $50 \%$ médias e $25 \%$ fracas), pois as consideradas fracas para as classes fortes eram médias para as classes médias, e fortes para as fracas.

As demais classes dos $2^{\circ}, 3^{\circ}$ e $4^{\circ}$ anos foram organizadas seguindo "os critérios de rendimento do ano anterior, cuja subjetividade foi contra balanceada por uma prova de testes pedagógicos", não sendo possível realizar a seleção de acordo com o estipulado pela psicotécnica, pois não houve tempo suficiente para conseguir os testes Dearbon (Fonseca, 1936, p. 8). Assim, a solução encontrada foi a utilização da "média das notas dadas pelas professoras" e o resultado dos testes. Essa medida contrariava o discurso da época sobre a subjetividade da correção de provas pelos professores, mas a diretora da escola tentava validar a iniciativa, afirmando que as notas dadas pelos professores coincidiram com os resultados obtidos via testes. Isto nos leva a conjecturar, baseado nos estudos de Julia (2001, p. 23) que novas práticas não eliminam por completo elementos de uma cultura anterior já estabelecida. Sempre há resistências e contradições que atravessam a aplicação de novas ideias, "novas restrições somam-se simplesmente às antigas". Isso justifica a posição da diretora de manter viva uma tradição que já ocorria em sala de aula.

\section{Mudanças na dinâmica do ensino}

Ao mesmo tempo em que a escola adotava os recursos psicológicos para a organização de classes seletivas, preocupava-se em medir o valor dos resultados do trabalho escolar, para crítica e organização da própria dinâmica do ensino. Dito de outro modo, se a escola mudava sua filosofia, deveria mudar também sua orientação, "pois a cada sistema de filosofia corresponde um sistema de educação e a todo sistema de educação corresponde uma teoria peculiar do ensino, e, até um gênero ou estilo de prática escolar" (Santos citado por Fonseca, 1936, p.10). Tratava-se, pois, de verificar o rendimento do ensino e aplicar métodos pedagógicos que melhorassem o desempenho dos alunos diante dos problemas diagnosticados.

Nesse sentido, as primeiras modificações se referiam ao programa de ensino que "à luz da psicologia genética foi alterado quantitativa e qualitativamente o seu conteúdo. Mínimos abrangendo aquilo que a criança pudesse aprender" e que atendessem "as possibilidades infantis" (Fonseca, 1936, p. 17). A diretora se referia ao programa mínimo organizado em 1934, na administração de Francisco Azzi ${ }^{12}$ e inspirado nas ideias de Decroly.

A este tempo, acreditava-se que o espírito se formava de dentro para fora, "pela excitação dos impulsos naturais que levam a fazer aprender". Essa nova maneira de pensar "alterou o mecanismo da aprendizagem", o interesse da criança ganhava papel de destaque (Fonseca, 1936, p.19). A nova dinâmica do ensino na Escola Normal de Casa Branca almejava a globalização das matérias e uma visão global dos planos de ensino, fundamentada nas ideias de Decroly. Mas não bastava classificar os alunos e modificar os programas de ensino, seria preciso alterar a dinâmica do trabalho escolar. Para isso, a escola procurou

\footnotetext{
${ }^{12}$ Diretor da Instrução Pública do Estado de São Paulo em 1933 e 1934.
}

Zetetiké, Campinas, SP, v.24, n.2, maio/ago.2016, p.225-236

ISSN 2176-1744 
http://periodicos.sbu.unicamp.br/ojs/index.php/zetetike

adequar as atividades desenvolvidas dentro da escola com a renovação pedagógica, a qual compreendia a educação como a própria vida. E, segundo Lourenço Filho (1930), preparar a criança para a vida era colocá-la "em condições de projetar, de procurar os meios da realização do projeto, de realizá-lo, verificar o valor de suas próprias concepções, emendálas, aperfeiçoá-las. Daí, como consequência natural, o sistema de projetos" [ênfase no original] (p. 169).

Ao contrário do ensino intuitivo em voga nas escolas paulistas, o qual levava a criança a observar, perceber, distinguir, discriminar, associar e "por si mesma comprehender, a lei, a causa, o geral, o abstrato", o ensino por projetos indicava um caminho oposto, levava à ação (Lourenço Filho, 1930). Segundo ele, para o ensino se configurar como um projeto, ele deveria conter quatro características:

1) A formação do raciocínio aplicado às realidades, não a informação de memória.

2) A informação, com oportunidade, para uma realização viva, não por si mesma: aprende-se para fazer, não se aprende para saber.

3) A aprendizagem realizada num ambiente natural.

4) O problema sempre antes dos princípios, nunca depois. ( p. 170)

Na tentativa de seguir esses pressupostos anunciados por Lourenço Filho, a Escola organizou o projeto "O clube agrícola", por se tratar de uma realidade da vida dos alunos e pelo fator econômico, visando à "sistematização de atividade futura, segundo padrão de vida superior, e solução do problema econômico - nacional" (Fonseca, 1936, p.18). Tratava-se de ensinar aos alunos um saber-fazer aplicado à prática cotidiana. O projeto foi subdividido em centros de interesses, para atender todo o ensino primário e organizado de modo a não perder de vista "o programa oficial das escolas primárias, garantia da homogeneidade cultural do nosso povo, dentro de um mínimo de instrução, além do qual, não se pode descer no estado atual da nossa civilização" (Fonseca, 1936, p. 17). O projeto "O clube agrícola" estava fundamentado nas ideias de Decroly, o qual acreditava que o conhecimento escolar estava nos programas comuns, com apenas uma diferença: a proposta de criação de laços entre as matérias e os diversos elementos de seu conteúdo.

Um dos centros de interesses desenvolvido pelo projeto foi a organização, pelos alunos do $4^{\circ}$ ano do ensino primário, de uma horta. Para a execução desse projeto, os alunos estudaram as necessidades do terreno, mão de obra, etc. E, tomando como base as figuras geométricas, eles realizaram cálculos para analisar o rendimento mecânico e manual para arar o terreno, e discutiram a melhor forma dos canteiros. Concluíram, após discussões, que o retângulo seria, então, a melhor medida por conta "da área por ele compreendida à perfeita concepção do metro quadrado" (Fonseca, 1936, p.19). 
http://periodicos.sbu.unicamp.br/ojs/index.php/zetetike

Além da questão dos métodos de ensino e dos programas, a renovação pedagógica previa a modificação do "horário mosaico" 13 em voga nas escolas tradicionais. Tratava-se de um horário que não levava em consideração as "creanças que aprendem, que são vivas, que se apresentam como um complexo de tendências e impulsos" (Lourenço Filho, 1930, p. 199). Para tanto, Lourenço Filho (1930) sugeria o programa Decroly, testado por Clotilde Rezzano $^{14}$ na escola experimental anexa à Escola Normal de Buenos Aires, pois o trabalho com centros de interesses não poderia se desenvolver com o "horário mosaico das escolas comuns, nem com o seu sistema de disciplina de symetria e silêncio"[ênfase no original] (p. 151).

Para atender ao projeto em desenvolvimento na Escola Normal de Casa Branca, a direção administrativa modificou o "horário-mosaico" das escolas comuns, inspirando-se em Decroly e Clotilde Rezzano, tal como propunha Lourenço Filho (1930). A Figura I mostra o modelo de horário estabelecido pela escola:

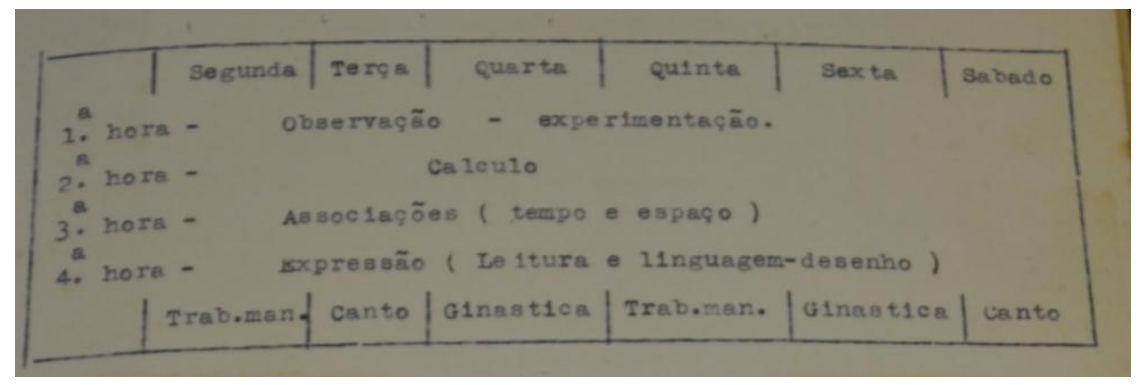

Figura 1 - Modelo do Horário seguido pela Escola Normal de Casa Branca Fonte: Fonseca, 1936, p. 20.

Como percebemos, esse horário segue as três bases do sistema de ensino defendido por Decroly: observação, associação e expressão. Em particular na observação, as lições de coisas tinham papel de destaque, em especial no ensino de cálculo, "primeiramente sob a forma de exercícios de comparação; depois, de medida com unidades naturais e, por fim, de medidas com unidades convencionais" (Lourenço Filho, 1930, p. 150).

\section{Vantagens da avaliação objetiva do trabalho escolar}

Como dito anteriormente, o objetivo dos testes pedagógicos era medir a eficiência do ensino das classes primárias. Nesse sentido, os testes estandardizados não seriam interessantes, pois mediriam além do que fora ministrado em classe. Assim se fazia

\footnotetext{
${ }^{13}$ A esse tempo denominava-se horário mosaico "a disposição usual de conceber um tempo determinado para cada uma das atividades escolares, arranjando-as em blocos cujo conjunto preencheria a totalidade do tempo escolar. Não se considera, em princípio, depois de fixada a distribuição dos blocos, a possibilidade de flexibilização do tempo para cada atividade nem a alteração na posição das peças que o compõem" (Souza \& Garnica, 2012, p. 500).

14 Clotilde Guillén de Rezzano (1880-1951), pedagoga argentina e defensora de ideias escolanovistas. Sua proposta pedagógica fundamentava-se nos centros de interesses.
}

Zetetiké, Campinas, SP, v.24, n.2, maio/ago.2016, p.225-236

ISSN 2176-1744 
http://periodicos.sbu.unicamp.br/ojs/index.php/zetetike

necessário construir os próprios testes, baseando-se no que havia sido ministrado no decorrer das aulas. Para a organização desses testes, a direção da escola realizou uma série de palestras sobre os testes de escolaridade, tomando como base o relatório produzido por Noemy Silveira Rudolfer $^{15}$ sobre o trabalho desenvolvido no SPA, em 1931. As experimentações realizadas nesse laboratório serviram de exemplos "para quaisquer outras iniciativas no Sistema Educacional no sentido de preparar pessoal para executá-las devidamente" (Monarcha, 2009, p. 9). Nessas palestras, foram discutidos os meios de avaliação (provas orais e escritas), os defeitos e as qualidades das provas escritas, as vantagens dos testes pedagógicos em oposição aos defeitos da prova escrita, a construção de testes e noções estatísticas. Ainda nessas palestras, os professores aprenderam a elaborar o quadro de especificações baseado nos conteúdos ministrados no curso primário. A orientação era desprezar as questões "de pouco ou nenhum valor e incluir as de maior importância" (Fonseca, 1936, p. 56). Assim o professor saía da "condição de auxiliar, para aquela de refletir sobre as questões a serem utilizadas" (Valente, 2014, p. 13).

Conforme a orientação aprendida nas palestras, os professores confeccionaram uma bateria de testes para verificar trimestralmente o rendimento dos alunos em todas as matérias do curso primário: história do Brasil, geografia, aritmética, linguagem e leitura silenciosa. Para medir o rendimento aritmético, foi elaborada uma bateria de testes composta por dez questões cada uma. Essa bateria era subdividida em duas séries: cálculo e problemas. A primeira testava a habilidade de efetuar as técnicas operatórias do cálculo, enquanto a segunda testava o raciocínio por meio de problemas selecionados em ordem crescente de dificuldade.

Segue exemplo de um teste elaborado para mensurar o raciocínio dos alunos do primeiro ano da escola primária e aplicado ao final do primeiro trimestre de curso.

1) 4 laranjas +3 laranjas +1 laranja $=\ldots$ laranjas.

2) Quantos pés têm 18 patinhos? ... pés.

3) 6 meninas quantas mãos têm? ... mãos.

4) Meia dúzia de facas $=\ldots$ facas.

5) 26 automóveis quantas rodas têm? ... rodas.

6) Comprei um doce por 4 tostões, uma fruta por 3 tostões. Quantos tostões gastei. Gastei ... tostões.

7) Alice ganhou 29 bolas deu 16 a seu irmão e ficou com ...bolas.

8) Tenho dois pratos com uma dúzia de ovos em cada um. Quantos ovos tenho? ... ovos.

9) Quantas orelhas tem 5 coelhinhos? ... orelhas.

10) José caiu e cortou 3 dedos dos pés e 2 das mãos. Quantos dedos bons tem José? ... dedos. (Fonseca, 1936, p. 79)

\footnotetext{
${ }^{15}$ Professora formada pela Escola Normal do Brás, assistente de Lourenço Filho na Cadeira de Psicologia e Pedagogia da Escola Normal da Praça entre 1927 e 1930, período em que auxiliou na padronização e na aplicação dos testes ABC. Em 1931, foi responsável pelas experiências desenvolvidas no Serviço de Psicologia Aplicada.
} 
http://periodicos.sbu.unicamp.br/ojs/index.php/zetetike

Apesar de os problemas terem sidos elaborados pelos professores da escola os resultados obtidos, conforme crítica dos avaliadores, não corresponderam às expectativas, pois não houve notas máximas, pelo contrário, predominaram as notas baixas. Além de as justificativas para as notas baixas serem a impossibilidade de seleção das questões, visto que os conteúdos não foram tratados em todas as classes do mesmo grau de ensino; e a linguagem utilizada nas questões ter sido considerada inadequada às crianças, os avaliadores pontuaram, ademais, que os problemas foram "um pouco fortes, pelo tempo de aula que as crianças tiveram". As críticas se referiam ao segundo, quinto e décimo problema. O segundo por se tratar de problema com "operação que leva resto", o quinto por solicitar "multiplicação por 4" e o décimo por envolver "raciocínio muito forte". De modo geral, esse teste abordou "itens do programa que só mais tarde, se esperava, fossem tratados. No entanto, autorizaram-nos a isso os quadros de especificação recebidos. Ainda aqui o desigual desenvolvimento do programa, dificultou a organização dos testes" (Fonseca, 1936, s/p).

O rendimento se apresentou melhor em cálculo do que nos problemas. A justificativa para tal resultado encontra respaldo nos estudos de Thorndike(1936) ${ }^{16}$, para quem, em se tratando do cálculo, os alunos se "bem motivados, a frequência das conexões - repetição garantiria a aquisição em vista”(p. 58). Quanto aos problemas, Fonseca (1936) diz que

a capacidade intelectual dos indivíduos, a sua habilidade técnica para dirigir o processo do pensamento, grandemente solicitada na resolução de problemas, marca as diferenças individuais com bastante sensibilidade. Mais (sic) é pequeno nas crianças o desenvolvimento do raciocínio, já pela falta de experiência, já pela dificuldade de abstrações. (p. 58)

Como percebemos, a escola encontrou muitas dificuldades na produção dos próprios testes. Ao que parece, essas dificuldades foram de adaptação dos problemas ao desenvolvimento psicológico da criança. Ainda que os problemas atendessem aos conteúdos especificados no programa escolar, as crianças precisariam de uma certa maturação para desenvolvê-los.

\section{Considerações finais}

$\mathrm{Na}$ análise que efetuamos dos documentos selecionados para compor esse artigo, verificamos que a Escola Normal de Casa Branca, visando seguir as ideias de renovação pedagógica, estava atenta ao movimento pedagógico internacional e nacional, que buscava tratar os problemas pedagógicos de modo científico, fundamentado em teorias psicológicas experimentais, sobretudo na aplicação de testes. Foram citados, no relatório por nós analisados, Decroly, Thorndike, Lourenço Filho, Noemy Silveira, autoridades no assunto na época, e as experiências que se desenvolviam no SPA.

\footnotetext{
${ }^{16}$ Edward Lee Thorndike (1874-1949), psicólogo americano, precursor do behaviorismo.
} 
http://periodicos.sbu.unicamp.br/ojs/index.php/zetetike

A renovação pedagógica englobava várias instâncias, desde a organização de classes homogêneas por meio de testes, passando por métodos de ensino, programas e horários, procurando obter melhores resultados no rendimento escolar. Percebemos também que as ideias para reorganização do ensino vieram da apropriação de experiências elaboradas em classes/escolas laboratórios, tais como: método Decroly, horário de Clotilde Rezzano e os testes estandardizados. E mesmo os testes elaborados pelos próprios professores da escola não ficaram isentos de uma cientificidade, eles não foram elaborados de qualquer maneira, buscaram nos métodos estatísticos o respaldo necessário.

Nos registros da diretora, evidencia-se também uma preocupação em conhecer o rendimento individual do aluno diante dos pontos abordados pelo professor durante as aulas, mas sem perder de vista o programa escolar em vigor. Verificamos por tentativas como essas que o foco principal da renovação não estava relacionado à aprendizagem do aluno - ainda que se considerasse o desenvolvimento psicológico -, mas à eficiência do ensino, no rendimento escolar. Isto se evidenciou no trato com a Aritmética, quando se procurou verificar o rendimento do aluno a partir do conteúdo abordado em classe, tendo em vista o programa escolar, em que as habilidades testadas foram as técnicas operatórias e o raciocínio por meio de problemas. Os maus resultados foram justificados pelo pouco desenvolvimento psicológico das crianças na execução dos problemas. Como vemos, ainda não estavam em foco as questões relativas à aprendizagem aritmética, o que se tinha era uma preocupação com a psicologia da criança em vistas a um maior rendimento do ensino.

\section{Referências}

Almeida Júnior. A. (1936). Advertência. In Uma Escola de Applicação. Boletim $n^{o}$ 9. São Paulo: Secretaria da Educação e da Saúde Pública.

Avanzinni, G. (1969). Alfred Binet et la pédagogie scientifique (M. Husson, prefácio). Paris: Librairie Philosophique J. Vrin.

Baptita, M. T. D. da S. (2001). Noemy da Silveira Rudolfer (1902-1988). In Campos, R. H. de F. (Org.), Dicionário biográfico da psicologia no Brasil. Rio de Janeiro: Imago; Brasília, DF:CFP.

Campos, R. H. de F.; Gouvea, M. C. S. \& Guimarães, P. C. D. (2014). A recepção da obra de Binet e dos testes psicométricos no Brasil: contrafaces de uma história. Revista Brasileira de História da Educação, 14(2), 215-242.

Chartier, R. (2002). História cultural - entre práticas e representações. Lisboa: Difel; Rio de Janeiro: Bertrand Brasil S.A.

Fonseca, M. A.(1936). Relatório das atividades desenvolvidas durante o ano de 1936, no Curso Primário Anexo à Escola Normal de Casa Branca. Casa Branca, SP. Acervo: Escola Caetano de Campos.

Julia, D. (2001). A cultura escolar como objeto histórico. Revista Brasileira de História da Educação, 1, 9-44. 
http://periodicos.sbu.unicamp.br/ojs/index.php/zetetike

Lourenço Filho, M. B. (1930). Introdução ao estudo da escola nova: bases, sistemas e diretrizes da pedagogia contemporânea. São Paulo: Melhoramentos.

Monarcha, C. (2009). Notas sobre a Institucionalização da Psicologia em São Paulo: o serviço de Psicologia Aplicada (1930-1938). Bol. Acad. Paul. de Psicol., 29(01), 7-15. Retirado em 13 outubro de 2015, de http://www.redalyc.org/articulo.oa?id=94611474002

NIihard, R. (1946). O método dos Tests: para iniciação dos professores (M. de Campos, trad.). São Paulo: Companhia Editora Nacional, 1946.

Pinheiro, N. V. L. (2015). O ensino de aritmética nas classes laboratório do curso primário anexo à Escola Normal Padre Anchieta. In Anais do XII Seminário Temático Saberes Elementares Matemáticos do Ensino Primário (1890 - 1971): o que dizem as revistas pedagógicas? (pp. 257-269), Pontifícia Universidade Católica do Paraná, Curitiba, Paraná.

Registro das Reuniões para pesquisas e estudos dos membros da Assistência Técnica de Psicologia Aplicada da Diretoria Geral de Ensino, 01/07/1931 a 14/03/1932. Acervo: Centro de Memória do Instituto de Psicologia da USP.

Souza, L. A., \& Garnica, A. V. M. (2012). Movimentos de um movimento: um estudo sobre os significados atribuídos ao escolanovismo e seus ritmos. Educ. Matem. Pesq., 14(3), 481-506. Retirado em 17 julho de 2016, de http://revistas.pucsp.br/index.php/emp/article/viewFile/12766/9357

Thorndike, E. L. (1936). A nova metodologia da Aritmética (A. Coelho, trad.). Porto Alegre, RS: Globo.

Valente, W. R. (2014). A era dos tests e a pedagogia científica: um tema para pesquisas na Educação Matemática. Revista Acta Scientiae,16, 11-26.

Submetido em: 20/02/2016

Aceito em: 07/07/2016 